(which is practised with the most modern methods and equipment). This is a very sensitive area for Saudi patients who consider inflicted self-harm a sin. For the overwhelming majority of patients, the therapist needs to demonstrate both knowledge and respect for their religious beliefs and values to be therapeutically effective. An example of this kind of problem is a patient insisting on fasting during the month of Ramadan (the fasting month for Moslems) while taking his lithium or else discontinuing it. The psychiatrist must demonstrate knowledge about general medicine and be able to provide concrete, practical discussion which are applicable to the kind of short-term treatment of patients that is familiar to the non-psychiatric physician. Females, as a rule, prefer a female therapist, whom they believe is more understanding and appreciative of women's problems. Luckily, there are more Saudi female physicians now than ever before.

Studies of traditional medicine as it pertains to psychiatry have just started as part of a big research project undertaken by King Saud University. Some liaison between physicians in private practice and health services in general is still lacking in Saudi Arabia. This increases the load on the already busy few psychiatrists and hence reduces the quality of follow-up. The important role of the extended family in providing support to its mentally ill members is made obvious by the high percentage of patients brought to emergency by their relatives and the reliance of the mental health system on their afterdischarge care.

Pasnau (1983) posed several questions regarding the implications for potential abuse of psychiatry, in the absence of mental health law and the possibility of developing new legal guidelines in the context of traditional Islamic law and customs in Saudi Arabia. This could be possible in the foreseeable future under the current Islamic resurgence movements and the trends of science Islamisation throughout the country.

\section{Acknowledgements}

I wish to thank Drs R. Chandrasena and V. F. Di Nicola for their continuing support and constructive criticism.

\section{References}

Al-Khani, M., Bebbington, P., Watson, J. \& House, F. (1986) Life events and schizophrenia: a Saudi Arabian study. British Journal of Psychiairy, 148, 12-22.

Chaleby, K. (1987a) Social phobia in Saudis. Social Psychiatry, 22, 167-170.

(1987b) Cousin marriages and schizophrenia in Saudi Arabia. British Journal of Psychiatry, 150, 547-549.

Conacher, G., Marazki, M. \& Evans, D. (1987) Acute dystonic reactions in Saudi Arabian psychiatric patients treated with haloperidol. Acta Psychiatrica Scandinavia, 75, 333-334.

DARADKeh, K. \& Al-ZAYER, N. (1988) Parasuicide in an Arab industrial community: The Arabian American Oil Company experience. Acta Psychiatrica Scandinavica, 77, 707-711.

El-Islam, M., Abu-Dagga, S., Malasi, T., Moussa, M. (1986) Inter-generational conflict and psychiatric syndrome. British Journal of Psychiatry, 149, 300-306.

El-Sayed, S., Maghraby, H., Hafeiz, H., Buckley, M. (1986) Psychiatric diagnostic categories in Saudi Arabia. Acta Psychiatrica Scandinavia, 74, 553-554.

GovindaSAMY, G. (1958) Cultural aspects of psychiatric illness. Journal of All India Institute of Mental Health, 1, 2.

MEHRAYAR, A. \& TAShakkori, G. (1978) Sex and parental education as determinants of marital aspirations and attitudes of a group of Iranian youth. Journal of Marriage and the Family, 40, 629-637.

MuRPhy, H., Wittakower, E. \& Chance, N. (1963) A cross-cultural inquiry into the symptomatology of depression. Transcultural Psychiatric Research Review, 1, 5-8.

Pasnau, R. \& Hartmann, L. (1983) Psychiatry in the Kingdom of Saudi Arabia. American Journal of Psychiatry, 140, 1493-1494.

$A$ full list of references is available on request from the author.

\title{
Links with child psychiatry in the USSR
}

\author{
Stewart Britten, Loughton Child Guidance Clinic, Essex
}

In 1988 the UK-USSR Medical Exchange Programme concluded an agreement with the Medical Association of the Union of Soviet Friendship Socie- ties on a rolling programme of exchange visits. The fields chosen for starting were mother and child health, with British specialists spending one to two 
weeks in the Soviet Union in 1989 and their Soviet counterparts coming to Britain in 1990 . The host group in each case was to organise a conference and professional visits.

Accordingly a party of 20 visited Moscow last summer. The group consisted mostly of paediatricians and obstetricians and gynaecologists, but also included a professor of child and adolescent psychiatry, another child psychiatrist, a district clinical psychologist and a principal child psychotherapist, three of whom had prepared conference papers. Sadly, their papers were never delivered. During the appallingly organised conference at the Institute for the Preservation of Mother and Child Health it gradually became clear that there was no interest in mental health issues, and despite prior agreement, no Soviet child psychiatrists or members of related professions had been invited to take part.

These exchanges in child psychiatry might have ended had not the smaller group which went on for a second week in Leningrad included a child psychiatrist - and had not the host organisation there, the city's health department, been helpful in arranging the visits which had been requested.

The programme included visits to one of the city's children's homes, a day nursery and a medical school. The 'home' housed 140 babies and children aged from ten days to four years - and there were 13 such homes in Leningrad, serving a population of five million. The total number of children in care, most presumably in homes for children aged five or older, could from this be calculated to be over 7,000. Dr Ludmila Rubina, head child psychiatrist of Leningrad, said there had been an increase in the last five years in numbers of babies taken into the homes-babies of unmarried mothers $(30 \%$ of mothers in Leningrad being single), of mothers from other republics of the union, of Russian mothers and African student fathers (there being much colour prejudice) and babies with neurological defects. The large number of these babies would appear largely to result from the low availability of contraception in the USSR.

Two of the city's homes for under-fives were for children judged to have neurological defects. Because these homes had one care worker on duty for each group of ten children, whereas in the 'normal' homes each worker had charge of a group of 20 children, the doctors (who seemed to have administrative rather than advisory roles) sought reasons to send children to the former, although their chances of adoption were then reduced to zero.

Dr Rubina and the head of the home were unhappy at the plight of the children in their care. But they had not heard of the work of Bowlby and continued to operate a system which separated children, at a stroke, when they reached the age of five from the only adults they had ever known. The play rooms were exceedingly tidy and some of the toys were screwed down. To a comment on the children's need for individual possessions, Dr Rubina replied laughingly that the children's home was a microcosm of what Soviet society was meant to be. The men in the party were met by muted cries of 'Dyadya' (uncle) from the toddlers, who were evidently only used to 'aunties'. The Intourist interpreter was in tears.

This, however, marks an improvement. Until some two years ago these homes would never have been shown to foreigners. Indeed, even Leningradians heard little of them.

Of as great cause for concern was Leningrad Nursery No. 196, which cared for 100 children up to the age of three. The childen were said to be 'normal', but looked dull and apathetic. The head seemed preoccupied with getting the children to adapt to the regime, and preferred to have babies start at seven or eight months old rather than later. The early starters were said to become more fit as well as better disciplined, but also more 'nervous'. The lack of care for the children's psychological development was in marked contrast to routine examinations by a panoply of specialists from neurologist to dermatologist. Indeed, the nursery worked with a paediatric neurologist in place of a child psychiatrist. There was not a child psychiatrist on the staff of the First Leningrad Medical School either, but Professor Clara Sergeyeva, head of the paediatric department, seemed to think that there should be. She was keen on exchanges with Britain; her medical school had taken part in no foreign exchanges.

For two generations conformity has been paramount in the Soviet Union. Adults may now speak out, but it seems that child rearing practices change more slowly. Parents are proud of their, usually single, well behaved children, and in the long struggle between grandmother and kindergarten for care of the preschool child, grandmother appears to be losing. The cost to the child of over-emphasis on conformity has yet to be widely recognised. In the meantime child psychiatrists may continue to be more agents for ensuring observance of norms than helpers for the child in overcoming blocks to his development.

But the head child psychiatrist was worried about children in care. Along with glasnost, or 'voiceness', there has begun an opening of the eyes. When a few Soviet child psychiatrists, possibly in the course of visits to Britain, see how the developments of two generations have passed them by, change may be rapid.

UK-USSR Medical Exchange Programme

9d Stanhope Road

London N6 5NE 